\title{
OPTIMIZATION OF LIQUID SCINTILLATION COUNTING CONDITIONS WITH TWO KINDS OF VIALS AND DETECTOR SHIELDS FOR LOW-ACTIVITY RADIOCARBON MEASUREMENTS
}

\author{
GEMMA RAURET, J S MESTRES and J F GARCIA
}

\author{
Radiocarbon Laboratory, Department of Analytical Chemistry \\ University of Barcelona - Institute of Catalan Studies, Barcelona, Spain
}

\begin{abstract}
Low-level radiocarbon measurements were made using two liquid scintillation (LS) counters, both with passive lead shields of approximately the same dimensions. The first one had a conventional background reduction with low-activity lead and "high-low" coincidence bias selection, and the second one had a spectrum analysis background reduction based on the different three-dimensional pulse-height signal of background and beta pulses.

The performance of commercial teflon-copper and glass vials were compared with both LS counters. Optimum counting conditions for the two detectors studied were also established. From results obtained, quality parameters and characteristics of quench curves were studied. Performances of each counter in the working conditions established were also compared.
\end{abstract}

\section{INTRODUCTION}

Liquid scintillation (LS) counting of low-level ${ }^{14} \mathrm{C}$ activity ensures the lowest detection limits as well as high-precision measurement. In our laboratory, we have tested two counters which have different background reduction design concepts. An LKB 1217 Rackbeta Kangaroo with a conventional passive low-activity lead shield surrounding the counting chamber, "high-low" coincidence bias selection, and the optimum use of teflon-copper (TC) vials for background reduction (Polach et al, 1983b; Calf \& Polach, 1974; Kuc \& Rozanski, 1978; Polach et al, 1983a; Rauret, Mestres \& Garcia, 1988). The other counter tested is a Packard TriCarb $2000 \mathrm{CA} / \mathrm{LL}$ with spectrum analysis which recognizes the different threedimensional pulse-height distribution of background pulses and ${ }^{14} \mathrm{C}$ beta pulses, thus reducing the background counts at the expense of efficiency (Operation manual TriCarb 2000/LL). This paper compares the performance of the two LS counters for low-level ${ }^{14} \mathrm{C}$ measurements under optimum conditions.

Quality parameters and characteristics of quench curves were also studied. One of the quality parameters calculated was the oldest attainable age that corresponds to the lowest measurable activity determined according to a defined criterion. The sample count rate was considered greater than background when the difference between both was larger than twice the standard deviation of the background (Stuiver \& Polach, 1977). The determination of ${ }^{14} \mathrm{C}$ activity by LS counting of pure benzene has the advantage of working under constant quench conditions. In practice, however, we realized that even under these conditions the spectral end-point of ${ }^{14} \mathrm{C}$ is not constant but presents some small variations (Rauret, Mestres \& Garcia, 1988), so that each counting vial must be individually calibrated based on external standard ratio determinations of counting efficiency. 


\section{EXPERIMENTAL}

We used two counters, an LKB-Wallac Rackbeta 1217 Kangaroo and a Packard TriCarb $2000 \mathrm{CA} / \mathrm{LL}$. The characteristics of the first counter are: high voltage stabilization circuit, "high-low" coincidence bias selection, linear amplification and logarithmic 256 channel spectra (1-2800 kev range) display, four independent channels with variable windows for data accumulation, automatic external standardization with a $\mathrm{Ra}-226$ source, and refrigeration $\left(10^{\circ} \mathrm{C}\right)$.

The characteristics of the second counter are: linear amplification, MCA of 4096 channels (1-2000 kev range) a variable range background discriminator based on the three-dimensional spectrum analyses SPECTRALYZER ${ }^{\mathrm{TM}}$, three independent regions with variable limits for data accumulation, external standard source of $\mathrm{Ba}-133$, spectrum storage possibility and refrigeration.

Two kinds of vials were used: teflon-copper (TC) $7 \mathrm{ml}$ (LKB-Wallac), modified (Rauret, Mestres \& Garcia, 1988) and the standard lowpotassium-content borosilicate $20 \mathrm{ml}$ glass vials (Packard).

We also used analytical reagents grade (AR), benzene and toluene (Carlo Erba, RPE) and ${ }^{14} \mathrm{C}$-labeled toluene (Packard). We prepared active toluene in benzene solutions of $2428.2 \mathrm{dpm} / \mathrm{ml} \mathrm{(A)} \mathrm{and} 3697.7 \mathrm{dpm} / \mathrm{gr}$ (B) from the previous solution. As quencher, solutions of $\mathrm{CCl}_{4}$ in benzene: 0.5 , $1.0,2.0$ and $4.0 \%(\mathrm{v} / \mathrm{v})$ were used. The four scintillators used were: commercial cocktail Instagel, butyl-PBD $(2.5 \% \mathrm{w} / \mathrm{v}$ and $5 \% \mathrm{w} / \mathrm{v}$ in benzene), PPO $(0.4 \% \mathrm{w} / \mathrm{v})$ in toluene and a mixture PPO $(0.4 \% \mathrm{w} / \mathrm{v})$ dimethylPOPOP $(0.01 \% \mathrm{w} / \mathrm{v})$ in toluene (all Packard).

The standard procedure employed $3 \mathrm{ml}$ of total counting solution obtained with $2.4 \mathrm{ml}$ sample benzene and $0.6 \mathrm{ml}$ of scintillator solution. In all cases, including commercial cocktail Instagel, we maintained the same 4:1 ratio between sample benzene and scintillator solutions. To carry out performance comparison of glass and teflon vials, we used solutions with PPOdimethyl-POPOP as scintillator and $3 \mathrm{ml}$ of total counting volume for the LKB counter and butylPBD and $4 \mathrm{ml}$ for the Packard counter. The blank was solutions with the same composition and conditions as the samples.

In the quenching efficiency correlation study, the standards were prepared as follows: for the LKB counter, $3.0 \mathrm{ml}$ of A solution, $0.4 \mathrm{ml}$ of butylPBD $(5 \%)$, variable volumes of $\mathrm{CCl}_{4}$ benzene solution and inactive benzene up to a total volume of $4.0 \mathrm{ml}$ were added to each TC vial. Twelve activity standard solutions with increasing $\mathrm{CCl}_{4}$ concentrations from 0 to $0.40 \%$ (v/ v) were obtained. For the Packard counter, $1.0 \mathrm{ml}$ of $\mathrm{B}$ solution was weighted in the glass vial previously tared; then the same procedures as before were followed.

With the LKB counter, the spectra were plotted manually 10 channels at a time. Overall counting time for the standard ${ }^{14} \mathrm{C}$ was $6 \mathrm{hr}$ and for the background 12-20 hr. With the Packard, the spectra were obtained with the low-level correction option and with a counting time of 2-4 hr for the standard ${ }^{14} \mathrm{C}$ and $6-12 \mathrm{hr}$ for the background.

For the study of the correlation between quenching and efficiency, the two sets of activity standards were counted for 10 periods of 10 min each, in 
the corresponding counters. The quenching parameter was provided by the external standard. For the LKB counter, an external standard channel ratio was used; the external standard window partition used is that which furnishes the maximum variation of the parameter between the less-quenched and the more-quenched solutions. The t-SIE parameter was used in the Packard counter.

\section{RESULTS AND DISCUSSION}

The following results were obtained from the integration of experimentally obtained spectra. In each case, the integration thresholds chosen as the optimum window were those which gave the best figure of merit.

\section{Performance of Glass and Teflon Vials}

The characteristics of TC and low-potassium borosilicate glass vials were compared in both counters. From the results obtained for background and efficiency, the figure of merit for each case was calculated. Table 1

TABle 1

Background, efficiency and figure of merit of glass and teflon vials

\begin{tabular}{lcccccc}
\hline & & LKB & & \multicolumn{3}{c}{ PACKARD } \\
& $\mathrm{B}(\mathrm{cpm})$ & $\mathrm{E}(\%)$ & $\mathrm{FM}$ & $\mathrm{B}(\mathrm{cpm})$ & $\mathrm{E}(\%)$ & $\mathrm{FM}$ \\
\hline $\begin{array}{l}\text { Type of vial } \\
\text { Glass }\end{array}$ & 2.36 & 33.8 & 483 & 1.92 & 69.8 & 2538 \\
Teflon-copper & 1.41 & 59.9 & 2548 & 3.38 & 61.8 & 1130 \\
$\begin{array}{l}\text { Scintillator } \\
\text { Instagel }\end{array}$ & 1.54 & 66.7 & 2890 & 0.64 & 52.1 & 4216 \\
Butyl-PBD & 1.78 & 72.5 & 2950 & 0.73 & 52.4 & 3760 \\
PPO & 1.43 & 59.3 & 2460 & 0.89 & 54.9 & 3403 \\
PPO+dimethyl- & & & & & & \\
POPOP & 1.33 & 54.6 & 2240 & 0.88 & 55.3 & 1726 \\
Volume & 1.78 & 72.5 & 2950 & 0.73 & 52.4 & 3760 \\
3ml & 2.47 & 73.7 & 2202 & 0.87 & 52.6 & 3168 \\
5ml & 3.39 & 73.8 & 1609 & 1.21 & 51.3 & 2165 \\
$7 \mathrm{ml}$ & & & & & & \\
\hline
\end{tabular}

shows the results. For the LKB counter, the figure of merit is much higher for TC vials than for glass because of the higher background count rate at low energies in the glass vials due to Cerenkov radiation. Figure 1 shows the spectra of the background for the glass and TC vials. For the Packard counter, on the contrary; the glass vials yield a much higher figure of merit than the one obtained with TC.

\section{Scintillator Effect}

Once the best class of vial for each counter was chosen, the effect of different scintillators on performance was tested. Table 1 shows results relating to efficiency (E) and background (B) and figure of merit for each counter and four scintillators. 


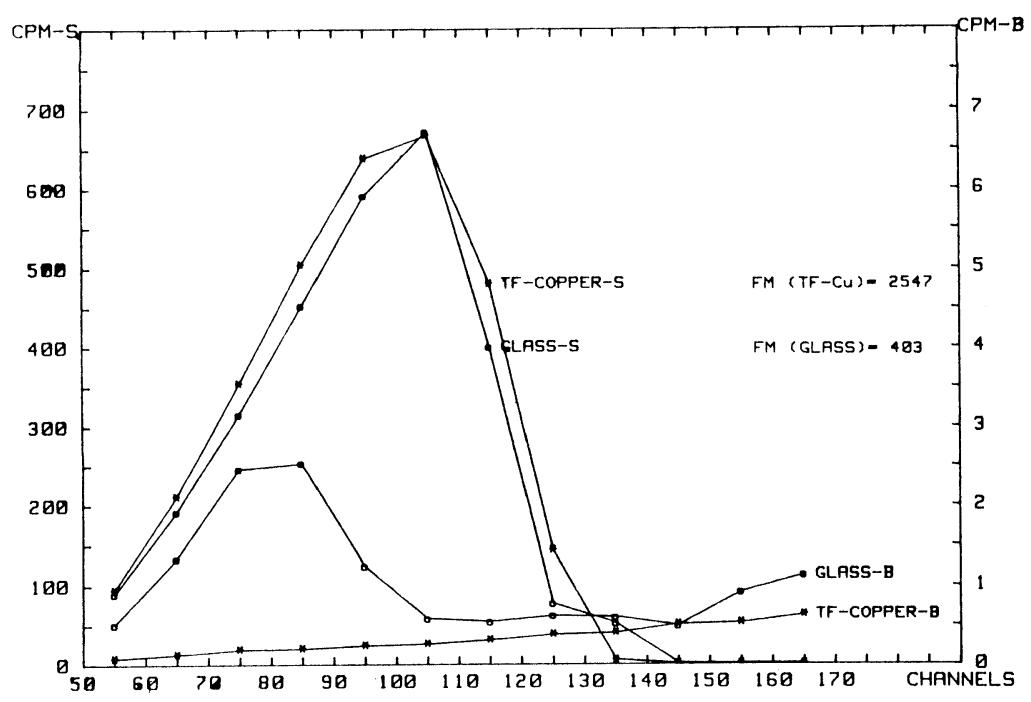

Fig 1. Radiocarbon (S) and background (B) spectra for glass and teflon vials

Based on the figure of merit, it can be concluded that for the LKB, as described earlier (Rauret, Mestres \& Garcia, 1988), butyl-PBD is the best scintillator, followed by Instagel, PPO and PPO + dimethyl-POPOP. These results agree with those found by Polach et al (1983). On the other hand, for Packard, the best scintillator is Instagel and the descending order of figure of merit is: Instagel $>$ butyl-PBD $>$ PPO $>$ PPO + dimethylPOPOP. Although the ${ }^{14} \mathrm{C}$ beta particle to photon energy transfer is better using butyl-PBD as scintillator, the shape of the ${ }^{14} \mathrm{C}$ spectrum in this counter shifted for Instagel to lower energy values, allowing us to work with a window for which the background is smaller for Instagel than for butyl-PBD with a similar efficiency. Under these conditions, the figure of merit for Instagel is better.

\section{Volume Effect}

In order to compare the volume effect, we chose butyl-PBD as scintillator for both counters.

It has been established previously (Rauret, Mestres \& Garcia, 1988) that, for the LKB counter, background increases linearly with volume whereas efficiency remains approximately constant with volume, so that the figure of merit increases when volume decreases. Similar behavior has been observed with the Packard counter. The values of efficiency (E), background (B) and figure of merit for both counters are also given in Table 1.

Considering that loss of sensivity occurs with small volumes of solution, we propose to standardize on a total volume of $4.0 \mathrm{ml}(3.2 \mathrm{ml} \mathrm{sample}+0.8 \mathrm{ml}$ scintillator solution). 


\section{Quench Correlation Curves}

If TC vials are used in the LKB counter, the quenching parameter ranges from 474 to 534. For glass vials with the Packard counter, this range is narrower, ranging from 769 to 813 . This has compelled us to study the correlation between efficiency and quenching for each counter in order to

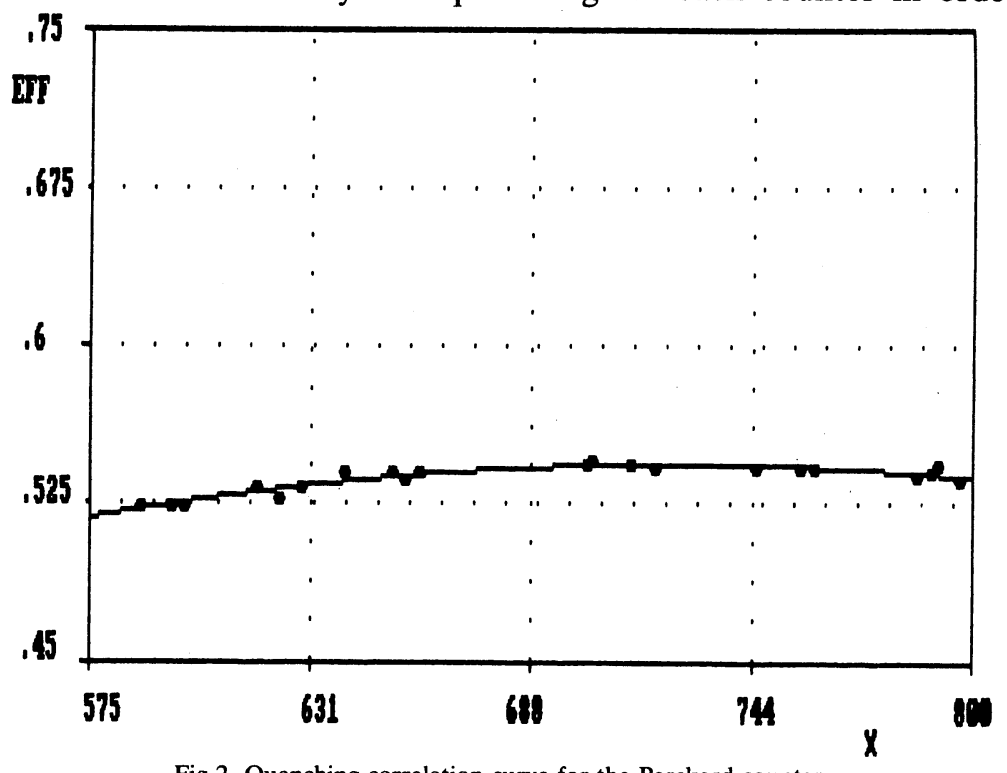

Fig 2. Quenching correlation curve for the Parckard counter

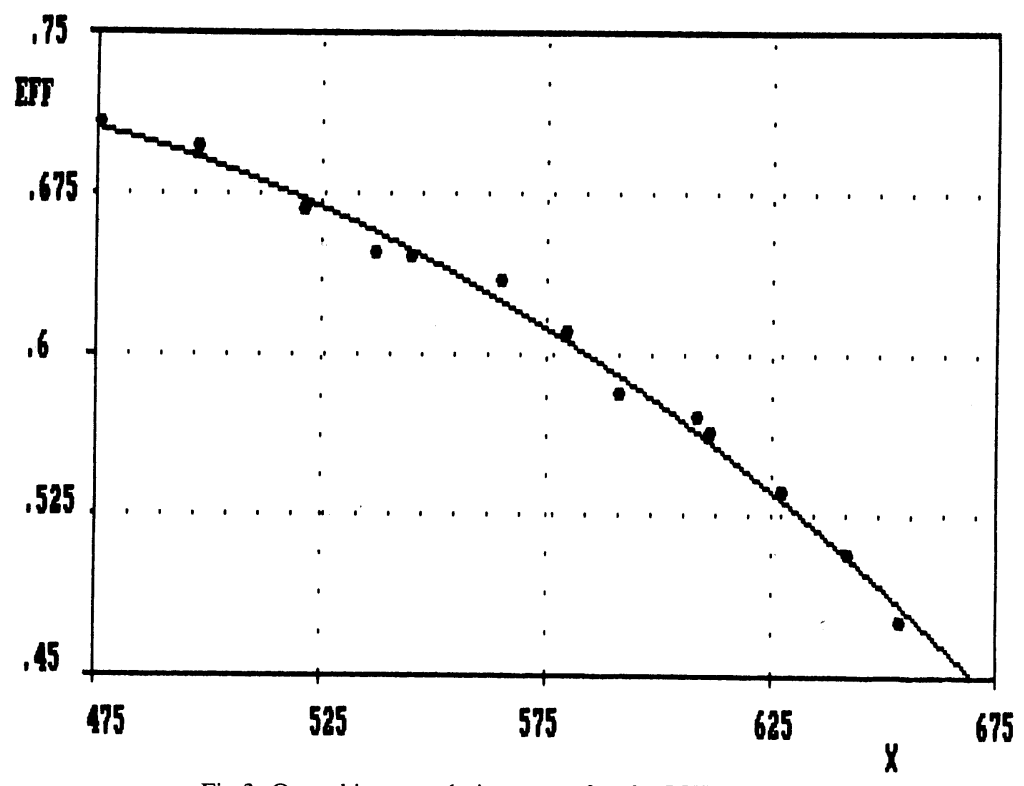

Fig 3. Quenching correlation curve for the LKB counter 
correct the small variations of efficiency in the working window. Figures 2 and 3 show the quenching correlation curves obtained for each counter. Efficiency drops quickly when the quenching increases for the LKB counter and it remains nearly constant in the quenching range studied for the Packard counter. In both cases, the working window used was that which gives the best figure of merit corrected for the possible interference of tritium. With the LKB counter, the possibility of using a window, the efficiency of which was not sensitive to small variations of quench, was rejected because of the drop of figure of merit obtained in these conditions, which was considered less advantageous for these kinds of measurements.

\section{Optimum Working Conditions for Both Counters}

From the results obtained in the previous sections, we have established the optimum working conditions for LKB and Packard counters to measure low-level activity ${ }^{14} \mathrm{C}$ samples. Table 2 gives these conditions.

TABLE 2

Optimum working conditions for the counters studied

\begin{tabular}{lllcccc}
\hline Counter & Vial & Scintillator & Volume & B(cpm) & E(\%) & FM \\
\hline LKB & Teflon-copper & Butyl-PBD & $3 \mathrm{ml}$ & 1.78 & 72.5 & 2950 \\
PACKARD & Glass & Instagel & $3 \mathrm{ml}$ & 0.64 & 52.1 & 4216 \\
\hline
\end{tabular}

\section{Oldest Attainable Age}

Let us assume that the smallest measurable activity is

$$
\mathrm{Am}=\frac{2 \mathrm{~S}(\mathrm{~B})}{\mathrm{a} \times \mathrm{E}}
$$

where $a$ is the weight of benzene measured and $E$ is the efficiency of counting. Then, the greatest attainable age is given by:

$$
\mathrm{t}_{\mathrm{m}}=\frac{5568}{\ln 2} \ln \frac{\mathrm{A}_{\mathrm{ON}}}{2 \mathrm{~S}(\mathrm{~B})} \mathrm{aE}
$$

According to this equation, the oldest attainable age may be calculated in two ways: with the theoretical standard deviation corresponding to background counting, and with the experimental standard deviation of the background. The oldest attainable ages for each counter in optimum working conditions with theoretical and experimental background standard deviations are nearly the same value for the LKB counter, 44,300 yr, and for the Packard counter, 45,000 yr, for theoretical (Poisson) and 41,100 for experimental. The experimental standard deviation gives, with the Packard counter, smaller values because the experimental standard deviation of the background is higher than the theoretical. 


\section{CONCLUSIONS}

For measurements of low ${ }^{14} \mathrm{C}$ levels, both counters perform well. Nevertheless, it is necessary to optimize conditions to attain lower detection limits. The main differences observed under optimal conditions are related to the vial and the scintillator. If we compare the performances of each counter with optimal conditions, we can conclude that the LKB has a more stable background but its efficiency is more dependent on the degree of quenching. Contrasting behavior is observed for the Packard counter.

\section{REFERENCES}

Calf, G E and Polach, H, 1974, Teflon vials for liquid scintillation counting of carbon-14, in Liquid scintillation counting: Recent developments: New York, Academic Press.

Kuc, T and Rozanski, K, 1978, A small volume teflon-copper vial for ${ }^{14} \mathrm{C}$ low level liquid scintillation counting: Internatl Jour Applied Radiation Isotopes, v 30, p 452.

Operation manual TriCarb 2000 CA/LL: United Technologies, Packard Instruments, Zurich.

Polach, H, Gower, J, Kojola, H and Heinonen, A, 1983a, An ideal vial and cocktail for low level scintillation counting, in Advances in liquid scintillation counting: Alberta, Univ Alberta Press, p 508-526.

Polach, H, Nurmi, J, Kojola, H and Soini, E, 1983b, Electronic optimization of scintillator counter for detection of low-level $\mathrm{H}-3$ and $\mathrm{C}-14$, in Advances in liquid scintillation counting: Alberta, Univ Alberta Press, p 420-442.

Rauret, G, Mestres, J S and Garcia, J F, 1988, Effect of counting vials and scintillators on the detection of low-level ${ }^{14} \mathrm{C}$ by liquid scintillation spectrometry: Nuclear Instruments \& Methods, v B34, p 373-376.

Stuiver, M and Polach, H A, 1977, Discussion: Reporting of ${ }^{14} \mathrm{C}$ data: Radiocarbon, v 19, no. 3, p 355-363. 